\title{
Non-biting flying insects as carriers of pathogenic bacteria in a Brazilian hospital
}

\author{
Henrique Borges Kappel ${ }^{[1]}$, Adriana Gonçalves Oliveira ${ }^{[2]}$, \\ Paulo Roberto da Silva ${ }^{[2]}$ and Afonso Pelli ${ }^{[2]}$
}

[1]. Doenças Infecciosas e Parasitárias, Universidade Federal do Triângulo Mineiro, Uberaba, MG. [2]. Instituto de Ciências Biológicas e Naturais, Universidade Federal do Triângulo Mineiro, Uberaba, MG.

\begin{abstract}
Introduction: Insects have been described as mechanical vectors of nosocomial infections. Methods: Non-biting flying insects were collected inside a pediatric ward and neonatal-intensive care unit (ICU) of a Brazilian tertiary hospital. Results: Most (86.4\%) of them were found to carry one or more species of bacteria on their external surfaces. The bacteria isolated were Gram-positive bacilli (68.2\%) or cocci (40.9\%), and Gram-negative bacilli (18.2\%). Conclusions: Insects collected inside a hospital were carrying pathogenic bacteria; therefore, one must consider the possibility they may act as mechanical vectors of infections, in especially for debilitated or immune-compromised patients in the hospital environments where the insects were collected.
\end{abstract}

Keywords: Microorganisms. Insecta. Public Health.

Some non-biting flying insects, particularly the common housefly (Musca domestica), have sporadically been described as possible mechanical vectors of agents of nosocomial infections because they may carry human pathogens and also due to their ubiquity including in the hospital environments ${ }^{1-4}$.

In Brazil, there are some reports showing that ants and cockroaches harbor pathogens in hospitals ${ }^{5,6}$, but there is no report on non-biting flying insects. Therefore, our aim was to investigate the presence of potentially pathogenic bacteria on the external surface of flying insects collected inside a Brazilian health care institution.

Flying insects were randomly collected in eight rooms of a pediatric ward and a neonatal intensive care unit (neonatalICU) of a Brazilian tertiary-care teaching hospital that has 290 beds. The insects were caught during their flight during different nights. Each insect collected was placed alive on to a 5\% sheep blood agar plate, allowing contact of its external surface with the culture medium. After removing the insect using sterile forceps, the plate was incubated at $37^{\circ} \mathrm{C}$ under aerobic conditions and was examined daily for bacterial growth. The insect samples were preserved in alcohol and subjected to entomological examination.

The morphology of isolated bacteria was observed using Gram staining. The Gram-positive cocci (GPC) or Grampositive bacilli (GPB) were separately cultured on sheep blood agar and the Gram-negative bacilli (GNB) on MacConkey

Address to: Dr. Henrique Borges Kappel. DIP/UFTM. Rua Getúlio Guaritá s/n, 38025-180 Uberaba, MG, Brasil.

Phone: 5534 3318-5258

e-mail: henriquekappel@hotmail.com

Received 31 May 2011

Accepted 08 October 2012 agar for further identification in species by using standard bacteriological procedures.

A total of 22 flying insects were collected: $5(22.7 \%)$ were caught inside the neonatal-ICU and $17(77.3 \%)$ in different rooms of the pediatric ward. They belonged to Diptera Linné, 1758 (9; 40.9\%), Hymenoptera Linné, 1758 (4; 18.2\%), Coleoptera (Linné, 1758) (3; 13.6\%), Lepidoptera Linné, 1758 (3; 13.6\%), Orthoptera (Olivier, 1811) (1; 4.5\%), Homoptera (Linné, 1758) (1;4.5\%), and Trichoptera Kirby, 1813 (1;4.5\%).

The Table 1 shows the insects and the isolated bacteria from insect samples, numbered from 1 to 22 . Among the 22 insects, $19(86.4 \%)$ were found carrying one or more species of bacteria on the external surfaces. Bacterial growth was not observed for 3 insects, 2 of the Diptera (supressão) and 1 of the Orthoptera (supressão). These three samples were caught in wards 84 and 86 on different nights (insect samples 2, 5 and 20), as demonstrated in Table 1.

The bacteria isolated from the sampling flying insects were GPB $(15 / 22 ; 68.2 \%)$, GPC $(9 / 22 ; 40.9 \%)$, and GNB (4/22; $18.2 \%$ ). One of the GPB isolated from a moth-fly (Telmatoscopus albipunctatus, Diptera) captured inside neonatal-ICU (insect sample 7) was identified as Nocardia cyriacigeorgica. The other GPB (14/22; 63.6\%) were spores forming of the Bacillus genus. All GPC isolated were coagulase-negative staphylococci (8/22; $36.4 \%$ ), except one, which was identified as Micrococcus spp. (insect sample 16). Three of the four GNB isolated belonged to Enterobacteriaceae family of the species Proteus mirabilis and Enterobacter gergoviae. One GNB was characterized as a nonfermented rod of the Pseudomonas genus (insect sample 15).

In our study, insects from Diptera (supressão) were found more frequently (40.9\%) inside the hospital than flying insects (supressão) such as Hymenoptera (18.1\%), Lepidoptera (13.6\%), and Coleoptera (13.6\%). We observed that flying 
TABLE 1 - Bacteria isolated from external surface of the flying insects caught at different sites in a Brazilian hospital according to the orders of the insects sampled

\begin{tabular}{|c|c|c|c|}
\hline Insect order (n/\%) & Sample & Hospital site & Bacterial isolates \\
\hline \multirow[t]{9}{*}{ Diptera $(9 / 40.9)$} & 1 & neonatal-ICU & GPB and GNB \\
\hline & 2 & room ward 86 & without growth \\
\hline & 3 & room ward 88 & GPB \\
\hline & 4 & room ward 93 & GPB \\
\hline & 7 & neonatal-ICU & GPB \\
\hline & 10 & room ward 79 & GPB and GPC \\
\hline & 15 & neonatal-ICU & GPB, GPC, and GNB \\
\hline & 20 & room ward 86 & without growth \\
\hline & 22 & room ward 92 & GPC \\
\hline \multirow[t]{4}{*}{ Hymenoptera (4/18.1) } & 8 & room ward 90 & GPB and GPC \\
\hline & 13 & room ward 86 & GPC \\
\hline & 16 & room ward 88 & GPB and GPC \\
\hline & 19 & room ward 88 & GPC \\
\hline \multirow[t]{3}{*}{ Coleoptera (3/13.6) } & 11 & room ward 79 & GNB \\
\hline & 14 & room ward 93 & GPB \\
\hline & 21 & neonatal-ICU & GPB and GPC \\
\hline \multirow[t]{3}{*}{ Lepidoptera $(3 / 13,6)$} & 12 & room ward 88 & GPB \\
\hline & 17 & room ward 86 & GPB \\
\hline & 18 & neonatal-ICU & GPB and GNB \\
\hline Orthoptera $(1 / 4,5)$ & 5 & room ward 84 & without growth \\
\hline Homoptera $(1 / 4,5)$ & 6 & room ward 92 & GPB \\
\hline Trichoptera $(1 / 4,5)$ & 9 & room ward 78 & GPB and GPC \\
\hline Total & 22 & & 28 \\
\hline
\end{tabular}

Neonatal-ICU: neonatal intensive care unit; GPB: Gram-positive bacilli; GNB: Gramnegative bacilli GPC: Gram-positive cocci.

insects were present in all rooms of the pediatric ward selected for sampling insects and also inside the neonatal-ICU. Likewise, other studies conducted in different countries have demonstrated that dipteran insects can be found inside hospitals $\mathrm{s}^{1-4}$. Smarova et al. ${ }^{7}$ found several other synanthropic arthropods inside several wards of a hospital but the most frequent were cockroaches and dipterans.

The majority $(86.4 \%)$ of the flying insects collected in our study were carrying bacteria on their external surfaces. The presence of bacteria in the insects caught from outdoor or indoor hospitals sites is very common. Fotedar et $\mathrm{al}^{2}{ }^{2}$ showed that flies caught from hospitals had a bacterial load higher than controls caught in a remote residential area. In contrast, Rahuama et al..$^{5}$ reported that insects from hospitals had a bacterial load similar to those from outdoors suggesting that isolated bacteria of the insects represents the sanitary conditions of the environment. However, insects are very mobile, having access to human feces, garbage, open wounds, and contaminated medical instruments acting as a link between infected and uninfected areas inside a hospital environment or outside.
As reviewed by Graczyk et al. ${ }^{9}$, some insects have structures on their legs coated with a sticky substance which facilitates the insects' adherence on non-horizontal surfaces and enhances the adhesion of particles such as bacteria and other microorganisms. Small particles may also readily adhere to an insect's exterior surfaces due to their electrostatic charges. Thus, bacteria that have adhered superficially may be transported to patients and hospital environments by insects. Moreover, the transmission of human pathogens by insects may also occur via mechanical dislodgement of the exoskeleton, fecal deposition, and regurgitation?.

In the present study, GPB of the Bacillus genus were the bacteria more frequently isolated from the surface of flying insects followed by coagulase-negative staphylococci ( $\mathrm{SCN})$, and GNB. These same bacteria were also isolated from the external surfaces and from the gut of several species of insects in other similar studies ${ }^{2,6}$. However, the majority of these studies observed a predominance of GNB. In our study, although only 4 out of $22(18.2 \%)$ of the insects collected harbored BGN, the species found (Proteus mirabilis, Enterobacter gergoviae and Pseudomonas spp.) are significantly important agents of various infections in humans, especially in hospitalized patients. Regarding to Bacillus spp., the virulence of these microorganisms varies according to the species. Bacillus anthracis and Bacillus cereus are medically important but other species may cause serious opportunistic infections. SCN are commonly found in the normal human microbiota but they also may cause opportunistic infections. Thus, the bacteria isolated in this study are relevant because of the existence of young, debilitated, and immunocompromised patients in the hospital sites where the flying insects were collected.

It should be emphasized that we isolated for the first time one Nocardia strain from an insect (Telmatoscopus albipunctatus, Diptera) that was captured inside the neonatal-ICU, although these bacteria had previously been isolated from dust and air in hospitals ${ }^{10}$.

Our results showed that synanthropic flying insects of different orders were found flying inside a tertiary-care teaching hospital in Brazil. The presence of these insects inside homes or hospitals is considered harmless by many people since they are very common in countries like Brazil with tropical climates ${ }^{11}$.

In general, they cause less discomfort than other pests such as cockroaches and ants also found inside hospitals. However, as we have demonstrated that flying insects collected inside a hospital in our country were carrying potentially pathogenic bacteria, one must consider the possibility that they may act as mechanical vectors of nosocomial infections. Therefore, despite the windows of the pediatric unit of the hospital where this study was conducted have screens on windows, more stringent measures must be taken to avoid the presence of the flying insects in the intensive care units and elsewhere in the hospital.

\section{ACKNOWLEDGMENTS}

We thank Claudia Rabbit (FIOCRUZ; Fundação Oswaldo Cruz, Rio de Janeiro, Brazil) for supporting in the identification of insects and the staff of the neonatal-ICU and the pediatric ward of University Hospital of the Universidade Federal do Triângulo Mineiro for cooperation in our study. 


\section{CONFLICT OF INTEREST}

The authors declare that there is no conflict of interest.

\section{FINANCIAL SUPPORT}

This research was supported by the Fundação de Amparo à Pesquisa do Estado de Minas Gerais (FAPEMIG); Fundação de Ensino e Pesquisa de Uberaba (FUNEPU) and Coordenação de Aperfeiçoamento de Pessoal de Nível Superior (CAPES).

\section{REFERENCES}

1. Faulde M, Sobe D, Burghardt H, Wermter R. Hospital infestation by the clusper fly, Pollenta rudis sensu strictu Fabricius 1794 (Diptera: Calliphoridae), and its possible role in transmission of bacterial pathogens in Germany. Int J Hyg Environ Health 2001; 203:201-214.

2. Fotedar R, Banarjee U, Samantray JC, Shirniwas. Vector potential of hospital house flies with special reference to Klebsiella species. Epidemiol Infect 1992; 109:143-147.

3. Rahuma N, Ghenghesh KS, Ben Aissa R, Elamaari A. Carriage by the housefly (Musca domestica) of multipes-antibiotic-resistant bacteria that are potentially pathogenic to humans, in a hospital and other urban environments in Misurata, Libya 2005. Ann Trop Med Parasitol 2005; 99:795-802.
4. Nmorsi OP, Agbozele G, Ukwandu NC. Some aspects of epidemiology of filth flies: Musca domestica, Musca domestica vicina, Drosophilia melanogaster and associated bacteria pathogens in Ekpoma, Nigeria. Vector Borne Zoonotic Dis 2007; 7:107-117.

5. Costa SB, Pelli A, Carvalho GP, Oliveira AG, Silva PR, Teixeira MM, et al. Ants as mechanical vectors of microorganisms in the school hospital of the Universidade Federal do Triângulo Mineiro. Rev Soc Bras Med Trop 2006; 39:527-529.

6. Prado MA, Gir E, Pereira MS, Reis C, Pimenta FC. Profile of antimicrobial resistance of bacteria isolated from cockroaches (Periplaneta americana) in a Brazilian health care institution. Braz J Infect Dis 2006; 10:26-32.

7. Srámová $H$, Daniel M, Absolonová V, Ddicová D, Jedlicková Z, Lhotová $H$, et al. Epidemiological role of arthropods detectable in health facilities. J Hosp Infect 1992; 20:281-292.

8. Pai HH, Chen WC, Peng CF. Cockroaches as potential vectors of nosocomial infections. Infect Control Hosp Epidemiol 2004; 25:979-984.

9. Graczyk TK, Knight R, Gilman RH, Cranfield MR. The role of non-biting flies in the epidemiology of human infectious diseases. Microbes Infect 2001; 3:231-235.

10. Pelli A, Kappel HB, Oliveira AG, Silva PR, Dourado PL, Bataus LA. Characterization of a Nocardia sp. isolated from an insect (moth-fly) captured in a university hospital. J Hosp Infect 2007; 67:393-396.

11. Pelli A, Oliveira AG, Silva PR, Kappel HB. Adhesive cards for monitoring flying insects in a neonatal intensive care unit in a hospital in the Triângulo Mineiro Minas Gerais Brazil. Biotemas (UFSC) 2012; 25:199-201. 